\title{
Spatio-temporal variation of the stress field in the Wenchuan aftershock region*
}

\author{
Feng Long ${ }^{1, \star}$ Guixi $\mathrm{Yi}^{1,2} \quad$ Xueze Wen ${ }^{1,3}$ and Zhiwei Zhang ${ }^{1}$ \\ ${ }^{1}$ Earthquake Administration of Sichuan Province, Chengdu 610041, China \\ ${ }^{2}$ College of Geophysics, Chengdu University of Technology, Chengdu 610059, China \\ ${ }^{3}$ Institute of Earthquake Science, China Earthquake Administration, Beijing 100036, China
}

\begin{abstract}
Focal mechanism solutions and centroid depths of $312 M \geq 4$ aftershocks from the 2008 Wenchuan earthquake sequence have been derived by CAP (Cut and Paste) method from broadband waveform data with relatively high signal-to-noise ratio (SNR). Following this, we have analyzed the distribution of focal depths and the stress tensors, as well as the types of focal mechanisms. The major results are: (1) different cross-sections show that the depth ranges of the aftershocks at the southern and northern ends of the aftershock area along the Longmenshan fault zone are wider than those on the central segment, where rare $M \geq 4$ aftershocks occurred at depths shallower than $10 \mathrm{~km}$. The main faults trend to the NW on the southern and central segments, and for the northern segment, no dominant trend direction has been determined; (2) stress tensor distribution demonstrates that the majority of the aftershock areas on the cross-section along the major axis are mainly under compressive stress perpendicular to the profile; however, for the areas near Lixian, Beichuan, Qingchuan and the shallow parts of its northern segment, large principal stress components are parallel to the major axis profile direction. On the cross-sections perpendicular to the major axis, the three areas above can be divided into two parts: one with dominantly compressional stress near the major faults of the Longmenshan fault zone on the SE side, and the other with NE-direction push along the fault zone on the NW side; (3) the stress tensor distribution in map view is very similar to those on the vertical cross-sections. In map view, the orientation of the principal compressional stress axis $S_{1}$ on the central segment of the aftershock area presents an SE-trending arc shape; (4) the stress tensor slices at different depths show that the orientation of $S_{1}$ axis mainly changes on the central segment and at the northern end, indicating that the two segments have different seismogenic structures at different depths; (5) with the exception of the northern end of the aftershock region, the orientation of the $S_{1}$ axis changes little during the early and late stages, illustrating the seismogenic structures are relatively stable; (6) preliminary analyses for the seismogenic structures at the northern end indicated that deeper strike-slip quakes occurred on the ENE-striking branch at first, and then the NNE-striking branch faults at the northern end were activated and generated a series of relatively shallow strike-slip earthquakes due to subsequent stress-triggering; (7) the aftershock triggering mechanism that occurred near Lixian is different between the shallow and deep depths, and between the early and late stages, indicating that the main faults and the branch faults responsible for aftershocks are at different depths. Consequently, the relaxation effect of the main shock particularly impacts the branch faults.
\end{abstract}

Key words: Wenchuan earthquake sequence; focal depth; focal mechanism solution; stress tensor; stress field

CLC number: P315.72 5 Document code: A

\footnotetext{
${ }^{*}$ Received 18 May 2012; accepted in revised form 22 August 2012; published 10 December 2012.

† Corresponding author. e-mail: longfeng1981@gmail.com

(c) The Seismological Society of China, Institute of Geophysics, China Earthquake Administration, and Springer-Verlag Berlin Heidelberg 2012
}

\section{Introduction}

As an important parameter for describing the dynamics and kinematics of seismogenic tectonics, focal mechanism solution is widely used to determine the type of structure (Zoback, 1992), analyze the geom- 
etry of the seismogenic structure (Long et al., 2010; Song et al., 2012; Yi et al., 2012), calculate regional stress inversion (Gephart and Forsyth, 1984; Michael, 1984), and to facilitate earthquake prediction (Chen, 1978; Ma et al., 1994). The Wenchuan $M_{\mathrm{S}} 8.0$ earthquake on May 12, 2008 occurred in the central-northern Longmenshan fault zone, and produced a typical mainaftershock type sequence (Jiang et al., 2008) with an abundance of aftershocks. Until June 30, 2011, more than $400 M_{\mathrm{S}} \geq 4.0$ aftershocks were recorded, including 39 of $M_{\mathrm{S}} 5.0-5.9$, and 8 of $M_{\mathrm{S}} 6.0-6.4$. Some early research has been made about the focal mechanism solutions of the sequence. For example, $\mathrm{Hu}$ et al. (2008) calculated the focal mechanisms for 44 strong early aftershocks using the $\mathrm{P}$-wave first motion method, and concluded that although the main seismogenic faults are thrust faults, the focal mechanisms are different near Lixian and at the northern end of the aftershock area. Zheng et al. (2009) inverted the focal mechanisms of strong aftershocks $\left(M_{\mathrm{S}} \geq 5.6\right)$ by the CAP (Cut and Paste) method, and pointed out that the major faulting is thrusting on the southern segment and strike-slip on the northern segment. Wang et al. (2009) obtained 88 moment tensor solutions from time-domain moment tensor inversion, and found out that the aftershock region has obvious characteristics of segmentation based on the spatial distribution of the focal mechanisms. Zhang et al. (2010) got 829 mechanism solutions from the amplitude-ratio combined with the $\mathrm{P}$-wave first motion method, and discussed the temporal and spatial variation of the stress field in the aftershock region.

The seismogenic structure of the Wenchuan earthquake, which occurred within the NE-striking Longmenshan fault zone, is at the boundary zone between the South China block and the Bayan Har block at the northeastern margin of the Qinghai-Xizang plateau. This region has a complex structure, and has suffered a long evolutionary history (Burchfiel et al., 1995). It consists of three major active faults, almost parallel to each other (Wang et al., 2001): from the NW to SE, they are the Wenchuan-Maoxian fault (back-range), which has had no surface rupturing, but has shown severe secondary geological disasters; the Yingxiu-Beichuan fault (central-range), which is the major seismogenic structure of the Wenchuan mainshock, including a length of about $235 \mathrm{~km}$ of co-seismic surface rupture along this fault; and the Guanxian-Jiangyou fault (front-range), on which surface rupture is about $60 \mathrm{~km}$ long (Xu et al., 2009). The three imbricate faults thrust and superimpose to the Sichuan basin, forming the first-order block border in Chinese mainland (Zhang et al., 2003). In addition, there are several active faults of different scales near the Longmenshan fault zone, such as the nearly EW-striking East Kunlun fault, NE-striking Longriba fault, the nearly NS-striking Huya and Minjiang faults in the north, and the NW-striking Miyaluo fault on the west side of the central Longmenshan fault zone.

\section{Data and method}

A total of $312 M_{\mathrm{S}} \geq 4.0$ aftershocks of digital waveforms with high SNR were collected within the period from the main event on 12 May 2008 to the end of June 2011, and a recent internationally popular method called CAP (Zhao and Helmberger, 1994; Zhu and Helmberger, 1996) was applied to calculate the focal mechanism solutions. The method divides the waveform into two parts: the body wave and the surface wave, and fits them with the same parts of synthetic waveforms. It can therefore eliminate the deviations caused by inaccuracy in Green's functions, the earthquake location, and velocity models. Experiments show that the method is independent of the accuracy of the velocity model (Zheng et al., 2009; Luo et al., 2010), and that the number and spatial distribution of stations involved in the calculation has little effect on the results (Long et al., 2010). Due to the fact that the surface wave is sensitive to the focal depth, the method can also be applied to obtain relatively more accurate centroid depth by comparing synthetic seismograms at different depths with the observed seismograms. In data processing, a 0.05$0.2 \mathrm{~Hz}$ and $0.05-0.1 \mathrm{~Hz}$ fourth-order Butterworth filter was applied to the body wave and the surface wave, respectively. The Green's function is calculated by the $f-k$ method (Zhu and Helmberger, 1996). Finally, we get the focal mechanism solutions and centroid depth of these earthquakes.

In recent decades, the method of stress tensor inversion from focal mechanism solutions has had a long-term development. In general, assuming a uniform distribution of the stress field in space (Angelier, 1979; Gephart and Forsyth, 1984; Michael, 1984; Gephart, 1990; Cui and Xie, 1999), however, for a strong earthquake sequence, a large variety of aftershock focal mechanisms can be attributed to the spatially varying stresses imposed by the dislocation of the mainshock (Das and Scholz, 1981; Stein and Lisowski, 1983; Oppenheimer et al., 1988). To solve the non-uniform stress field characteristics, Michael (1991) proposed the superposition stress inversion method (SSI), which is an 
inversion technique that solves for a uniform stress field superimposed on a given spatially varying stress field. The inversion provides the spatial position of three principal stress axes $\left(S_{1}, S_{2}, S_{3}\right.$, principal stresses ordered from most compressional to most dilatational) and their relative size $\varphi$, which is defined as

$$
\varphi=\frac{S_{2}-S_{3}}{S_{1}-S_{3}}
$$

It is in the range from 0 to 1 , ordered from uniaxial compression to uniaxial tension (Fossen, 2010); and the variance, which is defined as the solution misfit (the angle between the individual focal mechanism and the assumed stress tensor) squared and summed (Michael, 1991). Some researchers (Wiemer et al., 2002) believe that the variance represents the consistency of the stress field, which indicates the risk of potential earthquake hazard: the less variance, the higher consistency of the stress field, the more potential danger in the future. Previous work proved that the results from this method are accurate (Yi et al., 2012). We used this method to analyze the spatio-temporal variation characteristics of the stress field tensor in the Wenchuan aftershock region.

\section{Results and discussion}

\subsection{Stress field of the Wenchuan earthquake}

The distribution of the centroid depths of the $312 M_{\mathrm{S}} \geq 4.0$ earthquakes is shown in Figure 1. The sketch shows that the aftershock area can be divided into different portions based on the spatial distribution of the aftershocks, i.e., the southern segment of the west of Mianzhu with dense earthquakes, MianzhuBeichuan-Pingwu segment (central segment) with relatively dispersed earthquakes, the northern segment east of Pingwu where the NNE-striking aftershock area tends to significantly deviate from the Longmenshan fault zone. Such a distribution characteristic of epicenters is in good agreement with the previous precise relocation results of aftershocks (e.g., Huang et al., 2008).

In order to study the distribution characteristics of focal mechanisms of the Wenchuan earthquake sequence at different depths, we obtained seven vertical cross-sections on different portions and along different directions (Figure 1) as the projection plane for focal mechanism. In the cross-sections, $A A^{\prime}$ is along the major axis of the aftershock areas, and the rest are nearly perpendicular to the strike of the aftershock areas.

Figure 2 a gives the distribution of focal mechanism solutions on cross-section $A A^{\prime}$ along the strike of the seismogenic fault of the Wenchuan earthquake. It shows that earthquakes are concentrated at the depths less than $20 \mathrm{~km}$, and that dense aftershock distribution is

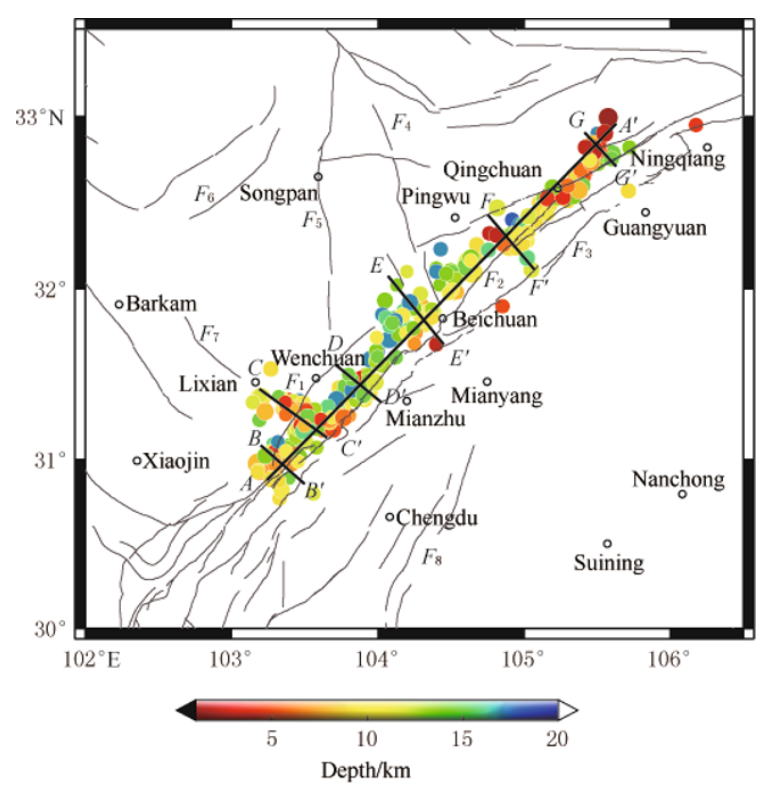

Figure 1 Map view of the centroid depths of the 312 $M_{\mathrm{S}} \geq 4.0$ earthquakes in Wenchuan earthquake sequence obtained by the CAP inversion and profile location sketch. $F_{1}$. Longmenshan back-range fault; $F_{2}$. Longmenshan central-range fault; $F_{3}$. Longmenshan front-range fault; $F_{4}$. Huya fault; $F_{5}$. Minjiang fault; $F_{6}$. Longriba fault; $F_{7}$. Miyaluo fault; $F_{8}$. Longquanshan fault.

within a relatively wide range of depths at both ends of the cross-section. Shallower earthquakes occur dominantly in the central portion of the section. In order to reflect the stress state on different segments of seismogenic faults, we have calculated the stress tensor and projected the orientation of the $S_{1}$ axis on the section $A A^{\prime}$. Considering the symmetry of the mechanical axis, the angle of the $S_{1}$ axis relative to the profile is limited in the range of $0^{\circ}-180^{\circ}$. It can be seen in Figure 2 a that the angles between the orientation of $S_{1}$ axis and the profile are within the range of $60^{\circ}-120^{\circ}$ for most of the region, i.e., the $S_{1}$ axis is nearly perpendicular to the strike of the profile. This shows that the approximately horizontal compressive stress direction is nearly perpendicular to the strike of seismogenic faults with dominantly thrust-faulting behavior. It is notable that the focal mechanisms display extension on the profile and the angle between $S_{1}$ axis and the profile is less than $30^{\circ}$ at the southern end near Lixian, the northern end near Qingchuan and the shallow part north of Qingchuan. This means that the principal compressive stress of the seismic source comes from the direction approximately 

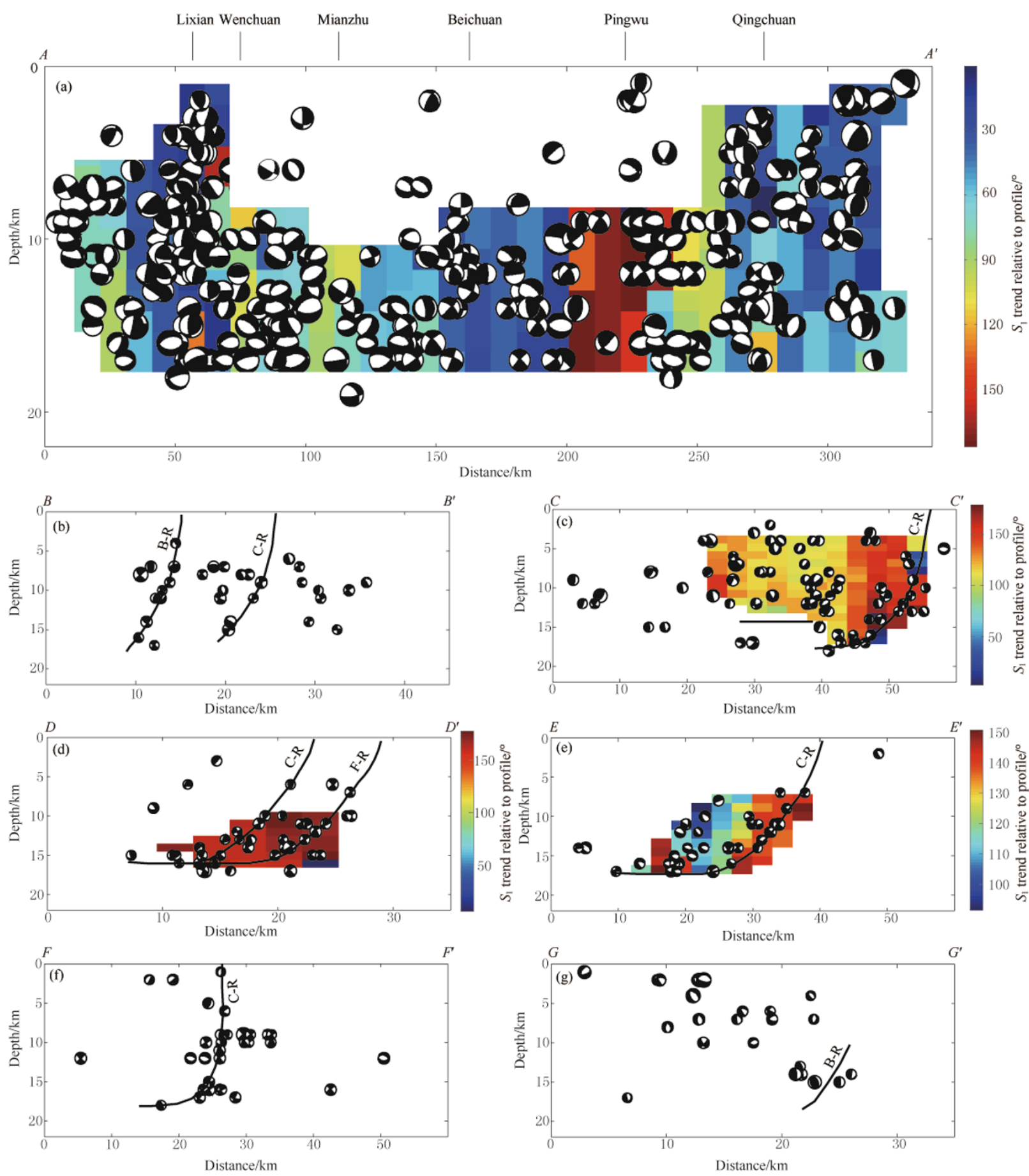

Figure 2 Vertical cross-sections $A A^{\prime}$ (a), $B B^{\prime}$ (b), $C C^{\prime}$ (c), $D D^{\prime}$ (d), $E E^{\prime}$ (e), $F F^{\prime}$ (f) and $G G^{\prime}$ (g) showing the focal mechanism solution projection and the angle of $S_{1}$ axis relative to the section. Projection width is $50 \mathrm{~km}$ on both sides of $A A^{\prime}$ section line, others are $20 \mathrm{~km}$. For $A A^{\prime}$, a fixed number of 15 earthquakes are used to calculate the stress tensor with slip-step $10 \mathrm{~km}$ and $1 \mathrm{~km}$ along the horizontal and depth, respectively. For $C C^{\prime}, D D^{\prime}$ and $E E^{\prime}$, fixed radius of 5 $\mathrm{km}$ and the sample size no less than 5 with slip step $3 \mathrm{~km}$ and $1 \mathrm{~km}$ along the horizontal and depth, respectively. The profiles $B B^{\prime}, F F^{\prime}, G G^{\prime}$ are with no calculation of the stress tensor due to dispersion of earthquakes. The solid lines mark the faults, where F-R, C-R, B-R represent the Longmenshan front-range, central-range, and back-range faults, respectively. 
parallel to the profile. In addition, for the BeichuanPingwu segment from $150 \mathrm{~km}$ to $220 \mathrm{~km}$ on the section, the direction of the principal compressive stress of aftershocks is generally parallel to the strike of seismogenic faults of the mainshock. This stress pattern reflects that dislocation type in the region is different from the Longmenshan fault zone, and implies different structures exist there.

The section $B B^{\prime}$ (Figure $2 \mathrm{~b}$ ) across the Longmenshan fault zone at the southern end of the aftershock area shows that the aftershocks are controlled by three main faults. Distribution of the aftershocks indicates a NW-trend of the main fault plane, and most aftershocks with a NW-trending plane also reflect the trend of the fault plane there. From the $P$-axis of focal mechanism solutions (Figure 2a), principal compressive stress is approximately parallel to the section $B B^{\prime}$, implying this segment of Longmenshan fault zone is under horizontal lateral compression.

The section $C C^{\prime}$ (Figure 2c) between Dujiangyan and Lixian crosses the southwestern segment of Longmenshan fault zone and its northwestern side. The aftershock distribution clearly demonstrates steep NWtrending fault planes of the Longmenshan central-range and front-range faults, which meet on the gently dipping basement detachment at a depth of $\sim 16-20 \mathrm{~km}$. From the stress state reflected by the stress tensor, the relatively large angle between the $S_{1}$ axis and the profile $C C^{\prime}$ (greater than $120^{\circ}$ ) indicates approximately horizontal pushing parallel to the profile. This evidence suggests that the main faults of the Longmenshan fault region are thrust faults under compressive stress. However, along the section $C C^{\prime}$ at the western side of Longmenshan fault zone southeast of Lixian, different mechanisms from $20 \mathrm{~km}$ to $40 \mathrm{~km}$ on the profile reflect the existence of different seismogenic structures with principal compressive stress perpendicular to the profile from the stress direction. Zhang et al. (2009) considered that the NW-striking tear faults perpendicular to the Longmenshan fault zone, triggered by the main shock, should be responsible for the aftershocks near Lixian.

The profile $D D^{\prime}$ (Figure 2d) crosses the centralsouthern segment of the aftershock area between Wenchuan and Mianzhu. Hypocenter distribution shows that fault plane there is significantly NW-trending, and the focal mechanism solutions demonstrate a compressive stress on the Longmenshan main faults.

The profile $E E^{\prime}$ (Figure 2e) of the central aftershock area crosses the Longmenshan fault zone near Beichuan, and demonstrates that the major seismogenic fault of the Wenchuan earthquake, i.e., the Longmen- shan central-range fault, has clear NW-trending features, with a dip smaller than those in sections $B B^{\prime}$ and $C C^{\prime}$. The depth of the basement detachment is about 15-20 km. Focal mechanism solutions reflect that under NE-directed shear stress, the Longmenshan fault zone is experiencing $\mathrm{NW}$-directed compression, which is similar to that on the section $C C^{\prime}$. The tectonic setting shows that the Longmenshan back-range fault has been interrupted here, and the southern branch of the Huya fault extends to the Longmenshan central-range fault on the central aftershock area and meets with the central-range fault at a right angle (seen in Figure 1). Stress loading mode on the NW side of the profile is different from the main faults, which may suggest that the southern branch of the Huya fault was involved in the aftershock activity there.

The profile $F F^{\prime}$ (Figure 2f), located at the centralnorthern segment of the aftershock area near Pingwu, displays the fault plane at depths shallower than $15 \mathrm{~km}$. It is relatively steep, with a minor NW-trend, and is relatively gentle at depth greater than $15 \mathrm{~km}$ from the hypocenter distribution. This finding is consistent with the precise relocation of Huang et al. (2008). From the stress state, with the exception of a few disperse aftershocks at depths shallower than $5 \mathrm{~km}$ having the principal compressive stress axis perpendicular to the profile, it is clear that the majority of the earthquakes were derived from the main faults under compressive stress state.

The northernmost cross-section $G G^{\prime}$ (Figure 2g) crosses the main faults near Guangyuan-Ningqiang with no surface rupture from the Wenchuan earthquake (Xu et al., 2009), and shows a complex fault system (Fan et al., 2008). Figure $2 \mathrm{~g}$ shows the hypocenters can be divided into SE and NW groups, in which the SE group includes six earthquakes with consistent mechanism solution located at deeper depths, and thrusting under the principal compressive stress mainly parallel to the profile. Comparing these with stress characteristics from the other sections, we consider that the six earthquakes may reflect the structural feature of the main faults at the northern end where shallow $M>4.0$ earthquakes are rare. In contrast, the aftershocks on the NW side of the profile are widely distributed in map view, and mainly occur at depths shallower than 10 $\mathrm{km}$. Two $M>6.0$ earthquakes occurred shallower than $5 \mathrm{~km}$, which is consistent with the result of Luo et al. (2010). Stress patterns perpendicular to the profile reflect NNW-striking fault-thrusting under NE-SW principal compressive stress, which triggered aftershock activity at the northern end of the aftershock area. 


\subsection{Stress field of the Wenchuan earthquake se- quence}

We have made slices of the stress tensor at different depths based on the inversion result in order to study different aspects of the stress state within the aftershock area of the Wenchuan earthquake. We divide the aftershock area into four parts based on the distribution of earthquakes, that is, the southern, central, northern, and NW-striking portions near Lixian (red dashed lines in Figures 3 and 4 as segment boundaries). We then calculated the average stress tensor for each portion and the results are shown in Figure 3.

From the stress tensor of earthquakes at depths shallower than $12 \mathrm{~km}$ (Figure 3a), the segmentation feature of aftershock area is obvious: the dominant orientation of the $S_{1}$ axis on the southern segment is NW-WNW, and close to that of the regional stress field (Cheng, 1981; Xu et al., 1987; Chen et al., 2001), indicating that this segment is under NW-WNW directed horizontal compressive stress state. Since less shallow earthquakes occurred on the Wenchuan-Mianyang and Beichuan-Pingwu segments, we did not get the stress tensor solution there. The dominant orientation of the $S_{1}$ axis near Beichuan is NE-SW on the NW side, and changes to EW near the main faults, implying that the southern branch of the Huya fault has affected the local stress field of the Wenchuan earthquake there. It is obvious that the orientation of $S_{1}$ axis changed from NE-SW to NW-SE on the northern aftershock zone near Qingchuan. The primary stress direction of the Qingchuan-Guangyuan segment is mainly oriented in the EW direction, while the NE orientation of $S_{1}$ axis at the northern end shows shear stress parallel to Longmenshan fault zone. The average tensors on the southern, central and northern segments are all typical of thrust faults, with nearly horizontal $S_{1}$ axes and vertical $S_{3}$ axes (Zoback, 1992). The differences are mainly embodied in the distribution of stress axis orientation, which has been well represented in the distribution of the $S_{1}$ axis orientation. The $S_{1}$ axis for the NW-striking portion near Lixian is nearly parallel to the strike of Longmenshan fault zone, which is consistent with the results from above cross-sections (see Figure 2c). The dips of maximum and minimum principal stress axes, $S_{1}$ and $S_{3}$, close to the horizontal, mean that strike-slip is the dominant dislocation mechanism, implying that seismogenic structures near Lixian are different from the main faults of Longmenshan fault zone. In addition, the
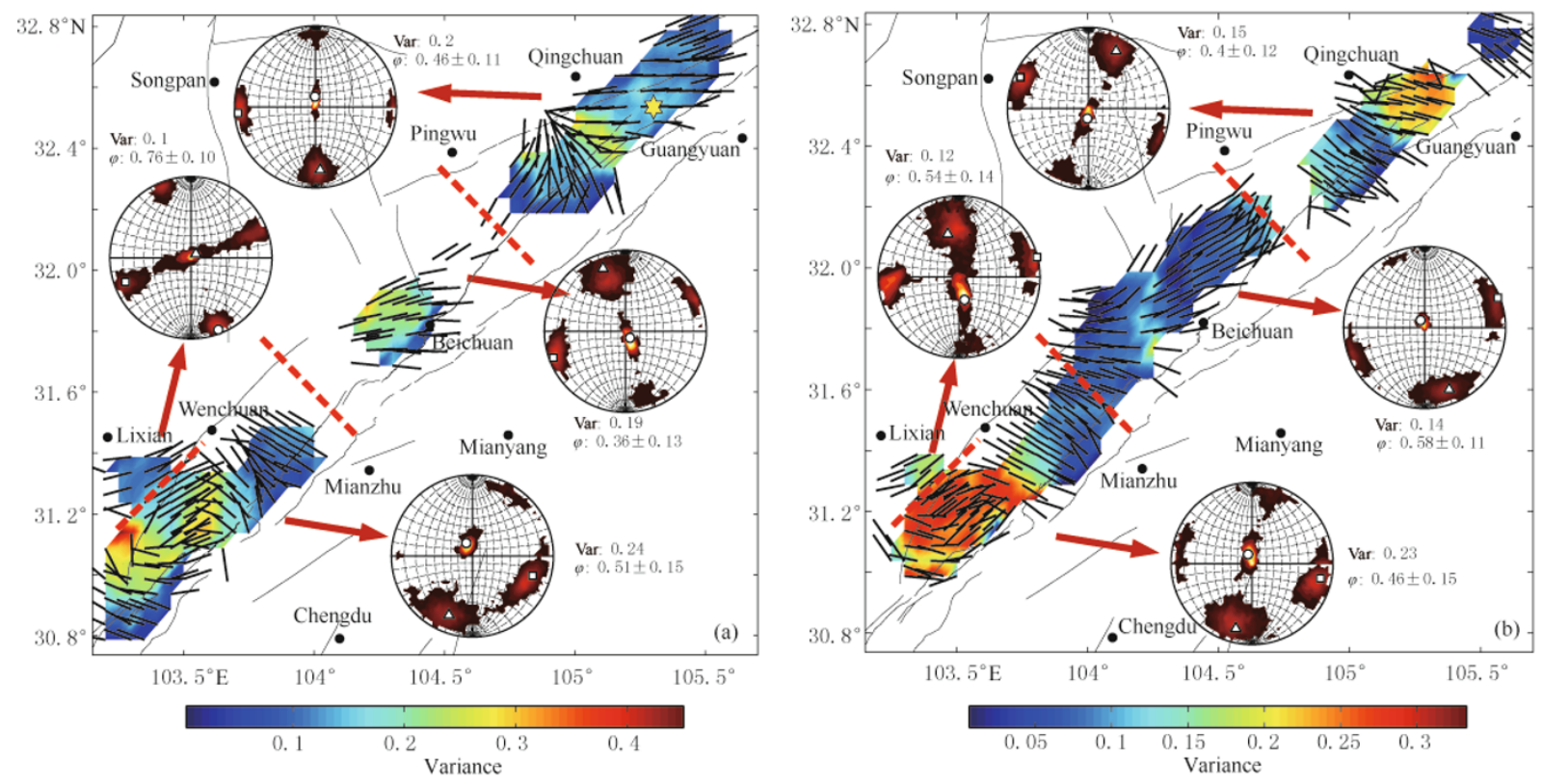

Figure 3 Map view of the orientation of $S_{1}$ axis and variance at depths shallower than $12 \mathrm{~km}(\mathrm{a})$ and deeper than $12 \mathrm{~km}$ (b), respectively, and the projection of principal stress axes for different segments on the Woolf net. A fixed sampling radius of $15 \mathrm{~km}$ is used in inverse, sample number shall not be less than 10 , sliding step is $0.05^{\circ} \times 0.05^{\circ}$. The red dashed lines represent the segment boundaries. Squares, triangles and circles represent the locations of axes $S_{1}, S_{2}$ and $S_{3}$ on the Woolf net. Yellow star marks the epicenter of the largest aftershock. The character "Var" means variance, which is defined in section 2, and $\varphi$ means relative size, which is defined in formula (1). 
variance of inversion, shown in the color maps, reflects the degree of consistency of focal mechanism solutions. It can be seen in Figure 3a that the variance is relatively high in the areas near Lixian, Beichuan and Qingchuan, which may be the result of different seismogenic faults intersecting in the depth range.

The stress tensor solutions at the depths larger than $12 \mathrm{~km}$ have some differences with those at the shallower depths (Figure 3b). Although the predominant orientation of the $S_{1}$ axis for the NW-striking portion near Lixian is NE-SW, the orientations of the $S_{1}$ axes near the main faults are disordered, resulting in relatively large inverse variance. The WenchuanMianyang segment is under compressive stress at depths greater than $12 \mathrm{~km}$ and lacks shallower earthquakes. On the Beichuan-Pingwu segment, the Longmenshan main faults are under shear stress parallel to the strike of the fault zone. The orientation of $S_{1}$ axis represents a SEtrending arc rotation. From Qingchuan to the north, the compressive stress field is oriented NW-SE, and is perpendicular to the strike of Longmenshan faults. The difference of focal mechanisms from the average stress tensor between deep and shallow depths is not so significant for different segments of the Longmenshan fault zone, as major faulting consists of thrusting under horizontal shear stress. The slight difference is that the azimuth of the $S_{1}$ axis on the northern segment changed from EW at shallow depths $(<12 \mathrm{~km})$ to WNW-ESE at deep depths $(>12 \mathrm{~km})$. However, the mechanism solutions near Lixian changed from strikeslip type to thrusting type (Figure 2c). Combined with evidence from the cross-section in the area, we find that most of the earthquakes on the tear fault near Lixian occurred at depth shallower than $12 \mathrm{~km}$, while the stress tensor solutions at the depth greater than $12 \mathrm{~km}$ may reflect the faulting type of the NW-trending main faults on the southern segment.

To investigate the temporal variation in the stress field, the sequence has been divided into two stages, before and after the end of July 2008, namely, the early stage (12 May 2008 to 31 July 2008) and the late stage (1 August 2008 to 30 June 2011). The results (Figure 4) show that, except in the Lixian area, no significant variation in the stress field between the two periods was observed. A slight difference exists at the northern end of the aftershock area, where the dominant directions of the main tectonic stress fields were EW and ESE in the early stage (Figure $4 \mathrm{a}$ ), reflecting the compressive stress on Longmenshan main faults, while the dominant directions changed to ENE in the late stage (Figure 4b). It is evident that the spatial distribution of aftershocks in the two stages had some differences.
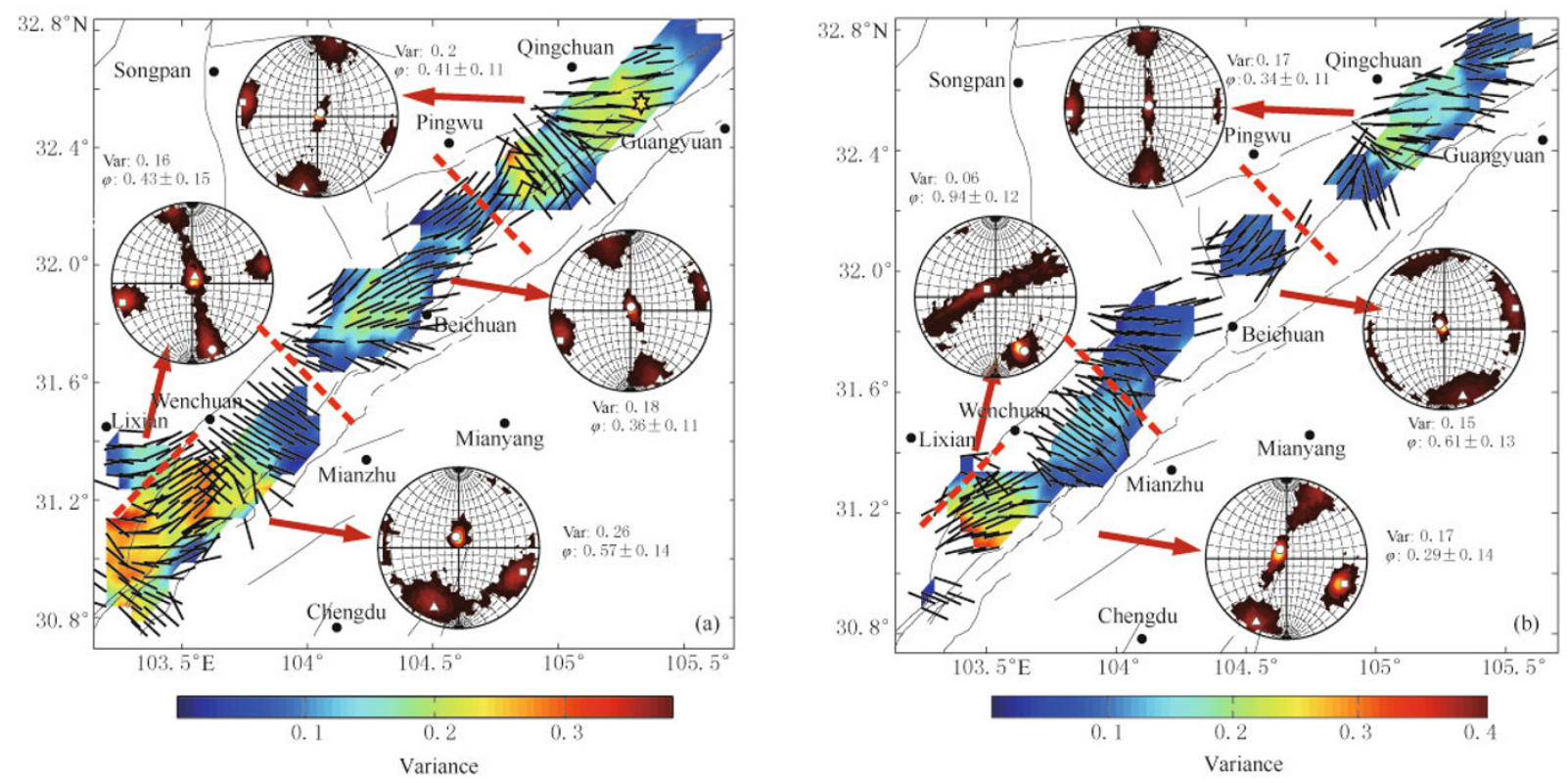

Figure 4 The map view of the azimuth of $S_{1}$ axis and the inverse variance before (a) and after (b) the end of July 2008. A fixed sampling radius of $15 \mathrm{~km}$ is used in the inversion, the number of samples is not less than 10 , and the space sliding step is $0.05^{\circ} \times 0.05^{\circ}$. The red dashed lines mark the segmentation boundaries. The squares, triangles and circles denote the locations of the $S_{1}, S_{2}$ and $S_{3}$ axes in the Woolf nets, respectively. The yellow star marks the epicenter of the largest aftershock. "Var" and $\varphi$ are the same as Figure 3. 
Aftershocks near the northern end, in the late stage, were located much more northward away from the Longmenshan fault zone than those in the early stage. The results of earthquake epicenter locating also showed that the aftershocks formed two branches trending NNE and ENE (Figure 5). Combined with results shown in Figure 3, we found out that the ENE branch of earthquakes happened first at deep depths is controlled by strike-slip faults, which seem not develop at shallow depths. The NNE branch of aftershocks then occurred at relatively shallow depths, and the direction of main tectonic stress was intersected in an acute angle by Longmenshan fault zone. These aftershocks may be related to branch faults within Longmenshan fault zone, which were triggered by the main shock. The mechanism type from the average stress tensor of aftershocks near Lixian also changed from strike-slip type to normal type. Whether this phenomenon is relevant to the relaxation effect from the great earthquake is a question for further study.

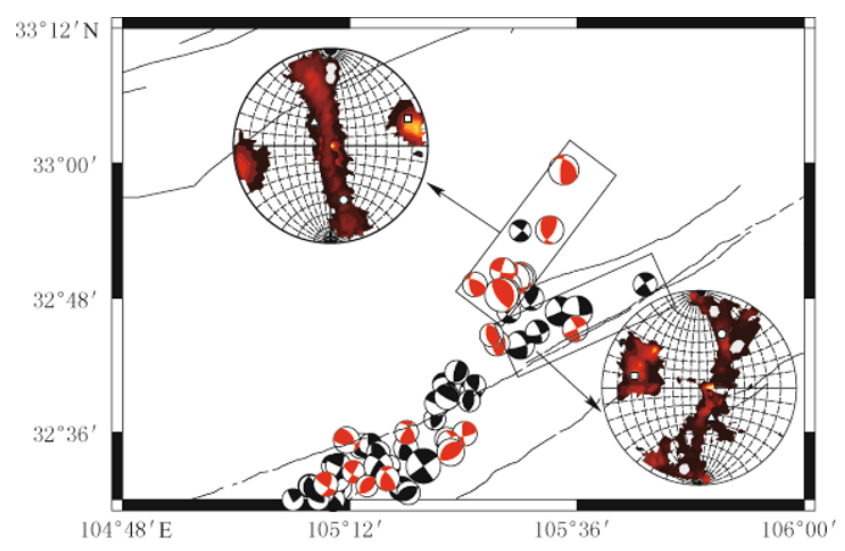

Figure 5 The distribution of the focal mechanism solutions in the northern aftershock area and the average stress tensor of the ENE and NNE branches of aftershocks. The black spheres in extensional area mark the focal mechanisms of earthquakes before the end of July 2008, and the red spheres mean those after July 2008. The squares, triangles and circles denote the location of the $S_{1}, S_{2}$ and $S_{3}$ axes in the Woolf nets, respectively.

\section{Conclusions}

In this paper, mechanism solutions and centroid depths of $312 M \geq 4.0$ aftershocks with relatively high signal-to-noise ration (SNR) waveforms of the 2008 Wenchuan, Sichuan, $M_{\mathrm{S}} 8.0$ earthquake sequence were derived by using the CAP waveform inversion method. Focal mechanism distribution on several sections across different parts of the aftershock area has been analyzed, and the stress tensors on the sections were inverted by the Michael inversion method to study the spatial and temporal distribution characteristics of stress field of the Wenchuan aftershock sequence. The main results obtained are as follows:

1) The aftershocks with size equal to 4.0 or above occurred at depths shallower than $20 \mathrm{~km}$, while the depth range of aftershocks on the northern and southern ends of the aftershock zone was relatively wide. On the central segment, shallow earthquakes at the depths less than $10 \mathrm{~km}$ were sparse.

2) Stress field calculations show that in the crosssection along the long axis of the aftershock area, most focal mechanisms indicate that the Longmenshan fault zone was under a compressive stress regime perpendicular to the strike of the Longmenshan fault zone. This evidence implies that the dominant type of faulting in Longmenshan fault zone was thrust. However, for the areas near Lixian, the Beichuan-Pingwu segment, and north of Qingchuan at shallow depths, the component of principal compressive stress was parallel to the strike of the fault zone, implying that there may be particular active structures. Moreover, along these sections perpendicular to the major axis of the aftershock area from SW to NE, the trend of faults on the southern and central segments of aftershock areas are obviously NW. On the northern segment, however, this trend was not obvious. All of the three profiles, located near Lixian, Beichuan, and at the northern end of the aftershock area, can be divided into two parts from stress field: one part under a compressive stress on the SE side near the Longmenshan main faults, and the other on the NW side, under shear stress parallel to the strike of Longmenshan fault zone. These two parts illustrated that the seismogenic structures in these areas were different from Longmenshan fault zone. Combined with geological data, we preliminarily consider that the NW-striking Lixian tear fault, the southern branch of Huya fault, and the other branch faults on northwestern side of the northern segment of Longmenshan fault zone, should be responsible for the different focal mechanisms in this area.

3) The map views of the stress tensor are similar to the cross-section results, which displays the orientation of $S_{1}$ axes perpendicular to the SE-striking main faults near Mianyang, parallel to the strike of Longmenshan fault zone near Beichuan, and finally perpendicular to the faults again near Qingchuan, forming a SE-trending arc. Map view and vertical cross-sections suggest that the compressive principal stress near Beichuan is parallel to the strike of Longmenshan fault zone, which 
is mainly reflected in the stress state of the southern Huya fault, while the orientation of the $S_{1}$ axis on Longmenshan main faults remained NW-SE. Such distribution may be due to the spatially scattered earthquakes with principal compressive stress parallel to the strike of Longmenshan fault zone. It also explains why the orientation of the $S_{1}$ axis was nearly parallel to the strike of Longmenshan fault zone on the central segment and the average stress tensor was thrusting. In fact, from the distribution of the $S_{1}$ axes, we can see that larger compressional components affect the main faults in the SE side near Beichuan.

4) The stress tensor sections at different depths showed that the orientation variation of $S_{1}$ axes mainly existed on the central and northern segments, indicating that the seismogenic structures on these two segments varied with depth. With the exception of the northern end of the aftershock zone, the orientation of $S_{1}$ axes in the remaining areas changed little between the early and late stages. Preliminary analysis of the seismogenic structure at the northern end showed that the strike-slip earthquakes occurred along deep-lying faults at first, and then the NNE-striking branch faults at the northern end were activated and generated a series of shallower strike-slip earthquakes due to the stress-release triggering from the main shock.

5) The average stress tensor solution on the NWstriking portion near Lixian showed the variation from strike-slip type at shallower depths to thrusting type at deeper depths, reflecting that the depth range of aftershocks on the NW-striking tear fault on the southern aftershock zone was different from that on the Longmenshan main faults. The variation from strike-slip faulting in the early stage to normal faulting in the late stage may be the result of the relaxation effect from the main shock.

Acknowledgements We thank Prof. Lupei Zhu for providing his CAP program to calculate focal mechanism solutions, Wiemer for his program ZMAP (Wiemer, 2001), Wessel for their GMT (Wessel and Smith, 1991) to calculate and plot stress tensor. We thank anonymous reviewers for their constructive comments. This work was supported by the projects from Ministry of National Science and Technology of China (Grant No. 2012BAK19B01-01) and National Basic Research Program of China (Grant No. 2008CB425701).

\section{References}

Angelier J (1979). Determination of the mean principal di- rections of stresses for a given fault population. Tectonophysics 56: T17-T26.

Burchfiel B C, Chen Z, Liu Y and Royden L H (1995). Tectonics of the Longmenshan and adjacent regions, central China. Int Geol Rey J 37(8): 661-735.

Chen T C, Horiuchi S and Zheng S H (2001). Earthquake focal mechanisms and stress field in Sichuan-Yunnan area determined using $\mathrm{P}$ wave polarity and short period $\mathrm{P}$ and S waveform data. Acta Seismologica Sinica 14(4): 466-470.

Chen Y (1978). Consistency of focal mechanism as a new parameter in describing seismic activity. Chinese $J$ Geophys 21(2): 142-159 (in Chinese with English abstract).

Cheng E L (1981). Recent tectonic stress field and tectonic movement of the Sichuan Province and its vicinity. Acta Seismologica Sinica 3(3): 231-241 (in Chinese with English abstract).

Cui X F and Xie F R (1999). Preliminary research to determine stress districts from focal mechanism solutions in Southwest China and its adjacent area. Acta Seismologica Sinica 12(5): 562-572.

Das S and Scholz C H (1981). Off-fault clusters caused by shear stress increase? Bull Seismol Soc Am 71: 1 6691675 .

Fan C, Wang E Q, Wang G and Wang S F (2008). Dextral strike-slip and tectonic transformation of the northern Longmen Shan fault belt from Late Neogene: A case study from the Qingchuan fault. Chinese $J$ Geology 43(3): 417-433 (in Chinese with English abstract).

Fossen H (2010). Structural Geology. Cambridge University Press, Cambridge, 69-96.

Gephart J W (1990). FMSI: A FORTRAN program for inverting fault/slickenside and earthquake focal mechanism data to obtain the original stress tensor. Comput Geosci 16(7): 953-989.

Gephart J W and Forsyth D W (1984). An improved method for determining the regional stress tensor using earthquake focal mechanism data: application to the San Fernando earthquake sequence. J Geophys Res 89: 9 3059320.

Hu X P, Yu C Q, Tao K, Cui X F, Ning J Y and Wang Y H (2008). Focal mechanism solutions of Wenchuan earthquake and its strong aftershocks obtained from initial $\mathrm{P}$ wave polarity analysis. Chinese J Geophys 51(6): 1 7111718 (in Chinese with English abstract).

Huang Y, Wu J P, Zhang T Z and Zhang D N (2008). Relocation of the M8.0 Wenchuan earthquake and its aftershock sequence. Science in China (Series D) 51: 1 7031711.

Jiang H K, Li M X, Wu Q and Song J (2008). Features of the May 12 M8.0 Wenchuan earthquake sequence and discussion on relevant problems. Seismology and Geology 30(3): 746-758 (in Chinese with English abstract).

Long F, Zhang Y J, Wen X Z, Ni S D and Zhang Z W 
(2010). Focal mechanism solutions of $M_{\mathrm{L}} \geq 4.0$ events in the $M_{\mathrm{S}} 6.1$ Panzhihua-Huili earthquake sequence of Aug 30, 2008. Chinese J Geophys 53(12): 2 852-2 860 (in Chinese with English abstract).

Luo Y, Ni S D, Zeng X F, Zheng Y, Chen Q F and Chen $Y$ (2010). A shallow aftershock sequence in the northeastern end of the Wenchuan earthquake aftershock zone. Science in China (Series D) 53(11): 1 655-1 664.

Ma J, Li Q Z, Diao G L and Yu L M (1994). Application of focal mechanism to earthquake prediction and its significance. Earthquake 14(S1): 27-34 (in Chinese with English abstract).

Michael A J (1984). Determination of stress from slip data: faults and folds. J Geophys Res 89: 11 517-11 526.

Michael A J (1991). Spatial variations in stress within the 1987 Whittier Narrows, California, aftershock sequence: new techniques and results. J Geophy Res 96(B4): 6303 6319.

Oppenheimer D H, Reasenberg P A and Simpson R W (1988). Fault plane solutions for the 1984 Morgan Hill, California, earthquake sequence: Evidence for the state of stress on the Calaveras fault. J Geophys Res 93: 9 0079026.

Song M Q, Zheng Y, Li B, Su Y, Wang X S, Lü F and Zhao X Y (2012). Discussion on focal mechanism solutions and seismogenic structure of 24 Jan 2010 HejinWanrong, Shanxi, $M_{\mathrm{S}} 4.8$ earthquake. Acta Seismologica Sinica 34(1): 111-117 (in Chinese with English abstract).

Stein R S and Lisowski M (1983). The 1979 Homestead valley earthquake sequence, California: Control of aftershocks and postseismic deformation. J Geophys Res 88: $6477-6490$.

Wang E Q, Meng Q R, Chen Z L and Chen L Z (2001). Early Mesozoic left-lateral movement along the Longmen Shan fault belt and its tectonic implication. Earth Science Frontiers 8(1): 375-384 (in Chinese with English abstract).

Wang Q C, Chen Z L and Zheng S H (2009). Spatial segmentation characteristic of focal mechanism of aftershock sequence of Wenchuan earthquake. Science in China (Series D) 54: 2 348-2 354.

Wessel P and Smith W H F (1991). Free software helps map and display data. EOS Trans AGU 72: 441, 445-446.

Wiemer S (2001). A software package to analyze seismicity: ZMAP. Seism Res Lett 72: 373-382.
Wiemer S, Gerstenberger M and Hauksson E (2002). Properties of the aftershock sequence of the $1999 M_{\mathrm{W}} 7.1 \mathrm{Hec}-$ tor Mine earthquake: implications for aftershock hazard. Bull Seismol Soc Am 92(4): 1 227-1 240.

Xu X W, Wen X Z, Yu G H, Chen G H, Klinger Y, Hubbard J and Shaw J (2009). Coseismic reverse- and oblique-slip surface faulting generated by the $2008 M_{\mathrm{W}} 7.9$ Wenchuan earthquake, China. Geology 37(6): 515-518.

Xu Z H, Wang S Y, Huang Y R, Gao A J, Jin X F and Chang X D (1987). Directions of mean stress axes in southwestern China deduced from microearthquake data. Chinese $J$ Geophys 30(5): 476-486 (in Chinese with English abstract).

Yi G X, Long F and Zhang Z W (2012). Spatial and temporal variation of focal mechanisms for aftershocks of the 2008 $M_{\mathrm{S}} 8.0$ Wenchuan earthquake. Chinese J Geophys 55(4): 1 213-1 227 (in Chinese with English abstract).

Zhang J L, Shen X H, Xu Y L, Gao Z W, Lü X J and Yang P X (2009). Surface rupture features and segmentation of the $M_{\mathrm{S}} 8.0$ Wenchuan earthquake. Earthquake 29(1): 149-163 (in Chinese with English abstract).

Zhang P Z, Deng Q D, Zhang G M, Ma J, Gan W J, Min W, Mao F Y and Wang Q (2003). Active tectonic blocks and strong earthquakes in the continent of China. Science in China (Series D) 46(Suppl.): 13-24.

Zhang Z W, Zhang Y J, Cheng W Z, Wu P, Long F and Ruan X (2010). Focal mechanisms and stress field of small earthquakes of the $M_{\mathrm{W}} 8.0$ Wenchuan earthquake sequence. J Seismol Res 33(1): 43-49 (in Chinese with English abstract).

Zhao L S and Helmberger D V (1994). Source estimation from broadband regional seismograms. Bull Seismol Soc Am 84(1): 91-104.

Zheng Y, Ma H S, Lü J, Ni S D, Li Y C and Wei S J (2009). Source mechanism of strong aftershocks $\left(M_{\mathrm{S}} \geq 5.6\right)$ of the 2008/05/12 Wenchuan earthquake and the implication for seismotectonics. Science in China (Series D) $\mathbf{5 2}(6)$ : 739-753.

Zhu L P and Helmberger D V (1996). Advancement in source estimation techniques using broadband regional seismograms. Bull Seismol Soc Am 86(5): 1 634-1 641.

Zoback M L (1992). First and second order patterns of stress in the lithosphere: the world stress map project. $J$ Geophys Res 97: 11 703-11 728. 